\title{
Using Patent Development, Education Policy and Research and Development Expenditure Policy to Increase Technological Competitiveness of Small European Union Member States
}

Simona Ferraro, Pawan Kumar Dutt and Tanel Kerikmäe

\section{Abstract}

The Chinese Belt and Road Initiative will open new trade routes between China and the European Union (EU) and increase competition pressures on smaller EU member states. This article ranks where states like Estonia stand internationally in terms of innovativeness (and consequent competitiveness) by conducting an econometric study of patent development, education policy and research and development (R\&D) expenditure policy. The authors claim that small member states such as Estonia should follow the example of countries such as Germany and adopt policies which focus more on increased public spending on R\&D and innovation in public universities of science and technology, and raise support for high tech startups with a strong focus on international patenting. Member States must go further and subsidise R\&D activities by focusing, inter alia, on filing of foreign patents such as triadic patents.

KEY WORDS:

Chinese Belt and Road, Estonia, R\&D, human capital, triadic patents, econometrics 


\section{Introduction}

The Chinese Belt and Road Initiative will undoubtedly open new trade routes between China and the European Union (EU). As stated by Geiger (2016) it will reduce shipping times for Chinese goods and this will make them more competitive on the European market.

In order to understand the impact of the Chinese Belt and Road Initiative on the EU's economy, it is important to note that among EU member states there exist fundamental and structural economic differences. Index Mundi (2017) states that per capita incomes vary vastly and there are divergent national attitudes towards foreign trade, inflation, etc. According to Eurostat (2017) the Euro area accounted for more than 70 percent of the EU's gross domestic product (GDP) in 2015 in terms of purchasing power standards (PPS). Interestingly however, the economies of the five largest EU member states stood at 67.6 percent of the EU's GDP.

Drawing comparisons on the basis of PPS, one sees that in 2015 GDP in the 28 member states of the EU was ahead of that of the United States (US). However, although historically China has had a lower level of economic output than both the EU and the US, the situation is now different. This could be attributed to the rapid transformation and great expansion of the Chinese economy. Thus, in 2015 China's economic output exceeded that of the EU according to Eurostat (2017).

The rapidly growing and transforming Chinese economy (influenced by the policies of the Chinese State) has helped to convert it into an industrial giant. In 2015 China was the EU's top partner for imports and the EU was the second largest destination for all Chinese exports. EU-Chinese trade in goods saw a deficit of 180 billion euro. Trade was dominated by machinery and vehicles. Every member state (except for Germany and Finland) experienced a deficit with China according to Eurostat (2017). Thus, the impact of China's exports on small and medium sized EU member states (whose economies are predominantly based on low cost labour practices and their resulting advantages), is likely to be even more substantial once the Chinese Belt and Road Initiative becomes fully functional. 
In order to overcome any underlying biases and to study the issue of competitiveness through the prism of objectivity and detachment, the authors want to study small EU member states like Estonia in the context of economic studies and particularly the utilisation of patents. The main research question of the paper is: how do investments in research and development (R\&D) and education have specific effects on the competitiveness ranking of diverse EU member states, when compared internationally? Or, more specifically, the authors want to answer the questions: "What is the relationship between patent development, education policy and R\&D expenditure policy when comparing small EU member states (with a focus on Estonia) with other countries which are members of the Organisation for Economic Co-operation and Development (OECD)?" And secondly, "How can the economies of small and medium sized EU member states escape any long term injurious consequences of the Chinese Belt and Road Initiative?" In this context, the authors want to understand and rank where small EU member states, like Estonia, stand internationally in terms of innovativeness (and consequent competitiveness). Next, the authors want to explore how such small EU member states can advance themselves by adopting a model of innovative growth, modeled after the most successful country in the EU (in terms of innovation and patenting). Finally, the authors will study the impact of Chinese economic trade in general, and the Chinese Belt and Road Initiative in particular, on the economies of small and medium sized EU member states. In doing so the authors will study how these states (especially Estonia) can prepare themselves to meet these challenges, and also transition from low wage and cost economies to highly innovative and competitive economies, by focusing on patent metrics.

\section{Estonia as a case study of EU member states with small economies}

Outside the top 5 EU economies (Germany, the United Kingdom, France, Italy and Spain), the picture of the economic and social setup of the remaining member states shows vast divergence. The authors have chosen Estonia for purposes of a case study. Estonia is a country situated in the 
north west of the EU. It has had a chequered history and was, until less than 3 decades ago, part of the Soviet Union. Since the collapse of the Soviet Union, Estonia has worked hard to break free from its recent past. Estonia is currently a member of the EU, the Euro Zone, the North Atlantic Treaty Organisation, OECD, etc. The country has undoubtedly made significant progress since the 1990s and has made deep strides in new areas such as information technologies, eGovernance, etc. This has also made Estonia a role model for the countries of the Eastern Partnership (Kerikmäe and Chochia 2016). It has been often debated whether Estonia is a Baltic or Nordic state, or in the category of being developing or developed. There are as many views on this topic as there are people. According to Europa (2017) Estonia's GDP was at $€ 20.461$ billion (2015) which is a small fraction of the GDP of the EU. In 2015, exports of goods from Estonia were approximately 11.6 billion euro, and imports were approximately 13.1 billion euro. Estonia's main trading partners were Finland, Sweden, Latvia and Germany. Almost 80 percent of total trade was with other EU member states. In 2015 exports from Estonia to EU countries was 8.7 billion euros. Imports from EU countries to Estonia were 10.8 billion euros. The Estonian Ministry of Foreign Affairs states that the main exports were machinery and equipment, wood (wood products), agricultural and food products, mineral products and miscellaneous manufactured articles.

\section{Background history of innovation and competitiveness in Estonian society}

The Estonian Patent Office provides the following information on its website, namely that it was established in 1919. The first Patent Act came into force in 1921 and focused on the protection of inventions, trademarks, patents, and models. Estonia joined the Paris Convention for the Protection of Industrial Property in 1924 and accepted all the rules and regulations conferred by the convention. Estonia also joined the Berne Convention for the Protection of Literary and Artistic Works in 1927. In 1937 a new Patent Act was adopted and came into force, together with the new Constitution in 1938. This act accepted the German patent system (Hoffmann and others 2012: 535-542). In the summer of 1940, after the occupation and annexation of the Republic of Estonia by the Soviet Union, the Patent Office was closed. After the end of World War Two Estonia was firmly in the clutches of the Soviet Union and communism. 
In the late 1980s, Soviet President Mikhail Gorbachov introduced reforms under the banner of perestroika. Intellectual property rights (IPRs) in the Soviet Union were sought to be westernised in 1991, so that individuals, including corporations, could own IPRs, instead of the Soviet State which had enjoyed exclusive ownership previously. However, the Soviet Union disintegrated soon thereafter and several Soviet Republics declared their independence in the summer of 1991. Although the Russian republic subsequently adopted new patent laws which were similar to those of the European Patent Convention and American patent laws, the Baltic states including Estonia did not wish to have any association with the former Soviet states and tried to move ahead on their own. As the rest of the world had economically developed while the Soviet states had suffered economic stagnation during the last stages of the Soviet era, it was clearly visible that experience and resources which are associated with industrial revolutions were lacking (Pitta 1992: 499).

The Estonian Patent Office states on its website that it was re-established in December 1991. On 1 May 2004, the Republic of Estonia acceded to the EU. Before that, the Estonian legal system of industrial property protection was harmonized with the requirements of the EU. In addition to the Paris Convention for the Protection of Industrial Property, the Republic of Estonia is also member to various multilateral international treaties in the field of industrial property. Regarding the future, the Estonian Patent Office is focusing mostly on efficiency and integration with international patent systems, rather than taking on new, large projects of their own.

\section{Literature review}

When it comes to the realm of studying relationships between patent development, education policy and R\&D expenditure policy, one can thankfully access detailed empirical literature in this field (Zhang 2011).

\section{a. Measuring technological change in society with the use of patents}


In today's modern paced societies, rapidly growing technologies, and especially fast evolving information and communications technologies, play a major role (Dutt and Kerikmäe 2014). One of the challenges with regard to patent data is as to how to utilise it as an information source for the purposes of measuring technological changes in society. It should be noted that almost all the available methods for measuring technological change are by their very nature an indirect measure of the process. There also exist heterogeneous metrics in this regard which can further complicate matters (de Rassenfosse and others 2013).

A patent can serve the twin objectives of being both a source of information of a technical nature and also as an indicator of technology. Some researchers have studied the relationship between technological change (as measured by patent statistics) and economic development, and have concluded that this can throw up some insightful observations about progress in society (Basberg 1987: 131). There is no doubt that patent statistics can be of great interest despite the difficulties which arise in their interpretation and usage (Griliches 1998). There has also been a greater integration of the university and industry sectors, where the emergence of intermediaries (incubators, science parks and technology transfer units) has led to increased knowledge and technology transfer (Kuttim 2016). This is of course distinguished from the relationship of trade and commerce with other types of IPRs such as trade marks, copyrights, etc., where the considerations (and outcomes) can be very different (Dobrin and Chochia 2016).

The analysis of the innovation process necessarily entails a deep study of the relationship between R\&D, patents and productivity (NymanMetcalf and others 2014). Such analysis can help us in the assessment and consequent evaluation of the output, which is linked to our study. Of course the use of patent statistics is not accidental. Patent statistics can be reasonably assumed to serve as a reflection of activities of an inventive nature and consequently leading towards innovation. Another factor of significance is the fact that there is no dearth of copious data in this regard. Patent statistics, by their very nature, lend themselves well to the act of comparing a wide spectrum of, not just industries, but also nations. Necessarily, this would hinge upon the basic question regarding the uniformity of the patent systems in these countries, or the amount of 
the uniform use of the patent system by the various industries which are to be compared against each other. One must not forget that an invention can very often be protected by using different techniques or facets of IP law (for instance by patenting the invention or simply maintaining it as a trade secret). Furthermore, the attitude towards the perceived utility of patents can also vary between different industrial sectors. When it comes to using patents for comparing countries, the principle of "like should be treated alike" is important. If diverse national patent institutions are not comparable amongst themselves in the first instance due to significant variances in practice or key legislational features, then to compare them may lead to faulty or invalid conclusions. In view of the above pitfalls, the use of patenting as a barometer for the observation and measurement of innovative processes must be undertaken carefully if it is to lead to substantial results (Basberg 1987: 132).

When it comes to considering whether patent filings or patents granted should be considered, then the former is preferred by some scholars on the grounds that different countries follow different criteria for patentability and also have different grant rates. Furthermore, patent offices are also known to undergo cycles of inefficiency which impact their "output" (de Rassenfosse and van Pottelsberghe de la Potterie 2009: 783).

It should be noted that there exists a factor known as technological specialisation. It is obvious that different industries will have different propensities towards patenting. Hence, if a country exhibits preferences for a particular set of technological specialisations then that may have an impact on the observed number of patent filings (de Rassenfosse and van Pottelsberghe de la Potterie 2009: 788).

Patenting has been successfully related in many models to the development phase as an output of R\&D activity. A positive relationship between R\&D and patenting has been the subject matter of various empirical studies (Basberg 1987: 133).

There exists a belief among some scholars that patent counts are reflective of a propensity to patent rather than being a variation in performance on an innovative level. Therefore in order to fully comprehend and decode the variations of patenting performance across national boundaries, 
would require a keen grasp of the varied factors that affect research productivity as well as the propensity towards patenting (de Rassenfosse and van Pottelsberghe de la Potterie 2009: 779). Different periods and fluctuations often also impact the economy (Männasoo and Meriküll 2014; 20111 .

\section{b. Studying research productivity or patent propensity}

Empirical results show that in order to determine the number of patents per researcher one must study the twin components of productivity and propensity, which in turn are influenced by the manner in which education, intellectual property and science and technology policies, are designed.

\section{Research productivity}

The conundrum of measuring research productivity is hard to solve, especially since the codification of a researcher's output is, by its very nature, intangible and not codified in a systematic manner.

i. One way of studying this problem has been forwarded by researchers such as Griliches, who has simplified the innovation process in order to measure the ultimate impact of innovative activity in terms of profitability or total factor productivity growth. However, such a study does not rely on a direct measure of the output obtained through innovative means, and is therefore inherently disadvantageous (de Rassenfosse and van Pottelsberghe de la Potterie 2009: 780).

During the course of his seminal work on this subject in the 1950s, Griliches noted that thanks to ever increasing funding by public and/or private bodies, expenditure on R\&D has grown at a rapid rate. However, it is not easy to judge in a quantitative manner what the results of such investments have been. An attempt to estimate the realised social rate of return on funding of hybrid-corn research in the 1950s showed some interesting results (Griliches 1958: 419).

Griliches determined that calculation of such a "rate of return" has been shown to be very similar to an approach based on the benefit-cost ratio 
method (Griliches 1958: 424). Furthermore, he devised that the rate of return of a successful innovation is calculated best if divided into two components: namely, in the first instance, the calculation of the rate of return if the development turns out to be a success and secondly, the calculation of the probability that it will be successful (Griliches 1958: 427). He stated that there is also the notion that there exists a difference between social and private rates of return, which must be adequately calculated in order to argue whether public investments trump private investments in R\&D or vice versa. For instance, in the field of hybrid-corn development, it was shown that the incentive for participation by private actors was restricted, since getting patents for the valuable ideas in this area was difficult, the short lifespan of the patents was a problem and the difficulties in procuring long term monopolies in this field were very high. Hence the social rate of return (as calculated) overshadowed the return on private investments in this sector. On the other hand, when nylon is studied as an example, then the private profits of its creator, DuPont, although not on par with the social returns, were nonetheless high enough to encourage the private sector to fund the R\&D of nylon (Griliches 1958: 430).

Griliches continued this line of research into the 1960s, where he determined that there existed different ways to measure output of R\&D. The "output" based on returns was further studied in later research, where an estimation of the aggregate agricultural production function based on US data, covering some years between 1949 up to 1959, to show the significance of education as a factor affecting output, indicated that public expenditures on agricultural research and extension (the dissemination of research results) affected the level of agricultural output significantly, resulting in a very high social rate of return. This study result was achieved by estimating an unrestricted production function of the CobbDouglas type, using separate variables for five major input categories plus a measure of education per worker and a measure of public expenditures on research and extension per farm, into the estimating equation. Studies such as these have served to define and measure different variables to show the contribution of public expenditures on agricultural research and on the dissemination of its results on the level of agricultural productivity (Griliches 1964: 961 - 962, 965). 
One of the calculations in the above study found a very high gross rate of return of 1300 percent for social investment in agricultural research and extension (Griliches 1964: 968).

In the 1970s, Griliches deduced that productivity and its growth can be discussed in the context of a "production function" (Griliches 1979: 93). He showed that the measurement of "output" in research and development intensive industries is affected by the fact that the products or services of those industries are themselves often measured inaccurately. Thus, for example, in the field of space exploration output is measured by mandays and expenditures on equipment and is not affected by success as such (Griliches 1979: 96). Furthermore, he stated that the measurement of research and development "capital" is in turn affected by the lag (i.e., the time, often in terms of years, taken by the R\&D process). Also of interest is the fact that past R\&D investments can be subject to depreciation and obsolescence. And very often knowledge from other sectors or industries is often borrowed or stolen. Thus one can see that the results of investments into R\&D are very often not observable in direct terms. Thus it could be considered that R\&D capital is something which can be viewed as an input measure (Griliches 1979: 100).

Calculation of relative returns to basic versus applied research, similarities/ differences between publicly and privately financed R\&D, measurement of the spillover effects of public R\&D spending, and the differences between economies of scale and productivity growth induced by R\&D are also of relevance (Griliches 1979: 109). He emphasised that questions also arise about the functional form of the production function, namely whether the different types of research are substitutes (where inputs are added together) or complements (where inputs are considered separately) (Griliches 1979: 110).

ii. A second approach is through reliance on innovation surveys in order to attempt to measure the output as a consequential share of a new or improved product or process innovation. The renaissance of manufacturing and re-industrialization on the Western economic agenda highlights the industrial sector as a special source of innovation and new product development, especially in the context of Industry 4.0 and smart factories, since industry generates $80 \%$ of the EU's private innovations 
and $75 \%$ of its exports (Prause 2015). Consequently, the assessment and benchmarking of innovation outputs will play an increasingly important role for smart manufacturing.

iii. Thirdly, patent based metrics have been used as an indicator. Studying patents often results in interesting outcomes since such a study is theoretically based on the view that effective research results in inventions, being an offshoot of the "productivity effect". In turn, such inventions could potentially lead towards patents if there exists, within the system, a propensity to patent. However one must be cautious about this approach since regarding research efforts as "inputs" into the invention production function, and viewing patents as necessarily being the "ouput", is often subject to empirical complexity, especially when one tries to separate the component of propensity to patent, from the component of research productivity (de Rassenfosse and van Pottelsberghe de la Potterie 2009: 780).

\section{Propensity to patent}

This is often determined by IP policy design. A classic example of this would be the fact that what is a patentable subject matter can often depend upon jurisdiction. Thus, certain technologies are unpatentable in Europe (eg. software alone without any technical effect, or certain gene related inventions) while on the other hand in the US the Supreme Court held in the Diamond v. Chakrabarty case that a large variety of inventions are patentable under the doctrine of "anything under the sun made by man". Furthermore, Science \& Technology policies influence institutions by determining whether their research is funded publicly or through private means, and/or whether they indulge in basic versus applied research. Thus the propensity to patent is affected if publicly funded basic research is oriented towards publications while business funded applied research and development is aimed towards the effective use of patented inventions. On the other hand, research productivity could also be affected by factors such as a high level of education in a country, since this is perceived as resulting in increased productivity of research activities, being an offshoot of stronger values of creativity, markedly improved skill sets or an increase in the overall capabilities to absorb new and trending technologies (de Rassenfosse and van Pottelsberghe de la Potterie 2009: 781). 
It should be noted that not all inventions end up being patented. This is an issue which can depend not only upon the particularities of the sector being studied but also the point of time when the investigation is undertaken. Thus, an invention can be protected either openly (by the use of the patent system) or secretly. This may be the case because the invention is not patentable itself due to specific legal considerations under patent law. Furthermore, there could be a variance in patent laws of different countries, despite the TRIPS agreement. Further new technologies (and inventions thereunder) - such as microelectronics or bio-technology - may be subject to ambiguity regarding factors such as novelty, inventive step and industrial applicability, which would therefore affect their chances of patentability (Basberg 1987: 133).

In view of the above, it is easy to see why some inventors prefer to maintain secrecy in respect to their inventions. Economic expectations can also play a role in this regard. If the process of patenting is deemed to be too expensive or the expected income in the form of sales, royalties, etc. are tinged with uncertainty or far less than the costs involved, then the incentive to patent would be lacking. Another reason which should be considered is that in certain cases a competitor may easily "invent around" the patent. Hence, a patent may only be successful in delaying an imitation of the invention by a short period of a few months, thereby rendering infructuous the option of patenting itself. The expected economic life of an invention also invariably plays a role in deciding whether the owner should go in for patenting or to maintain it as a trade secret. If the economic life of the invention is expected to last for longer than 20 years (the span of a patent) then obtaining a patent would not be a rational choice. Furthermore, in the case of new fields such as microelectronics, an invention gravitates towards obsolescence even before the patent application has proceeded towards being granted. In both cases maintaining secrecy thus becomes the preferred route in respect of protecting the invention (Basberg 1987: 134).

Recently, the importance of innovation communities for contemporary innovation management has grown due to increasingly complex, fast and interactive innovation needs, which requires the connection of 
external and internal knowledge bases (Prause and Thurner 2014). The phenomenon of "user-driven innovation" has to be taken into account as well. In contrast to the traditional practice that companies maintain their proper research facilities developing patentable innovation (or, in practice even more importantly, that they refer that to their pool of employees), "user-driven innovation" practices access the abundant consumerrelated knowledge pooled among consumers themselves. Consumers can be integrated into the innovation process mainly via information technology (Web 2.0) in the form of online communities. Consumers contribute in the form of comments, feedback or recommendations, to the company's profit, and "related topics like the protection of IPRs and the participation of user innovators in additionally generated company profits have recently been a major issue in the field of employee's inventions and non-affiliated private innovation contributions of any kind" (Hoffmann and Prause 2015: 134).

\section{d. The value of foreign patents}

There are many pros when it comes to studying patents which have been filed abroad. On the one hand this could have obvious implications for a business strategy which covers export markets (existing or potential). Licensing terms (in the context of production of goods) very often requires the contractual precondition of having a patent dealing with that particular product or process of manufacturing. More interestingly in our study, foreign patents serve the utility of being good indicators of technology. They are generally of a higher quality than domestically filed patents. In fact, one could even draw the conclusion that only those inventions which fulfill the criteria of high profit returns (or reasonable expectations thereof) are patented abroad. This would be necessarily so because of the time, effort and money spent on obtaining such patents (Basberg 1987: 136).

An important dependent variable is the number of patents filed and in which jurisdiction they are filed. Thus, the number of patents filed by the applicants from one country is sought to be utilised as a proxy for measuring the innovative performance of that country as a whole. This step requires careful choosing of the place of application for a patent. It would be usual for an Estonian applicant to apply for a patent in Estonia. 
This is known as a "home bias". Reliance on such a patent filing in Estonia is fraught with questions about its true value. Usually most studies are aimed at investigating patents filed either at the European Patent Office (EPO) or the United States Patent and Trade marks Office (USPTO), since they are perceived to be high quality patent applications with a higher market value. It should also be noted that patents filed there are subject to higher fees and translation costs. Hence the presumption that only the most valuable patents would be filed there. However, American or European patent applicants would have a higher propensity to file their respective patent applications in the USPTO or EPO, which would mean that their "home bias" is likely to skew the international comparisons which our study hopes to analyse. One way forward, as suggested by the OECD, is to utilise triadic patent families. These include only the patents that were filed simultaneously at the USPTO, EPO and the Japan Patent Office (JPO), and are thus a reliable measure of a perceived global protection strategy on the part of their applicants. The OECD database provides adequate and readily available coverage on such patent applications. Since they are translated and prosecuted in three different systems they are considered to be of high value and less susceptible to any potentially damaging "home bias" (de Rassenfosse and van Pottelsberghe de la Potterie 2009: 782).

In recent years, due to the availability of data, triadic patent families are being seen as especially useful for measuring patent data and drawing comparisons between different countries. By comparing multinational patenting activities in a third country, it is possible to delete those factors arising due to different national legislations, which cause difficulties concerning patents and their treatment thereof (Basberg 1987: 136).

\section{Development of the Model}

The empirical model chosen by the authors builds on the R\&D based growth model of Romer (Romer 1990). As Romer emphasizes, all types of knowledge share one essential feature: they are nonrival. Although all knowledge is nonrival, it is heterogeneous along a second dimension: 
excludibility. His model states that technology changes and this affects growth. Technology changes because people take recourse to actions intentionally as a response to incentives posed by the market. Replication of the designs for new products incur no additional costs.

The final output is produced according to a Cobb-Douglas production function which exhibits increasing returns to scale in all three inputs (because of the nonrivalrous nature of ideas):

$$
Y_{t}=K_{t}^{\alpha}\left(A_{t} L_{\gamma t}\right)^{1-\alpha} Y_{t}=K_{t}^{\alpha}\left(A_{t} L_{\gamma t}\right)^{1-\alpha}
$$

Where $K$ is the capital, $A$ is technology, $L$ is labour. Capital accumulation as in the Sodel:

$K_{t}=s_{K} \dot{Y}_{t}-\delta K_{t} K_{t}=s_{K} \dot{Y}_{t}-\delta K_{t}$

Where $\delta \delta$ is the depreciation rate and labour input grows at a constant rate $g(L)=n g(L)=n$. Labour is divided into production $L_{\gamma} L_{\gamma}$ and R\&D $L_{A} L_{A}$. Romer assumes that the growth rate of new ideas is proportional to the number of people trying to discover new ideas:

$\dot{A}=\bar{\partial} L_{A}$

Where $\bar{\partial} \bar{\partial}$ is the rate at which new ideas are discovered.

This model shows that to achieve perpetual economic growth, countries must focus on spending time, effort and money on activities such as R\&D. Human capital investment is also very essential.

\section{Selection of data}

Patent data is obtained from the OECD database on Patents by Technology. This paper studies the role of education and R\&D on patents for a group of 26 countries that are members of OECD for years 1990-2015. 
Countries studied are Estonia, Latvia, Finland, Sweden, Norway, Denmark, Germany, France, Italy, the United Kingdom, Luxembourg, Austria, Belgium, the Czech Republic, Greece, Hungary, Iceland, Ireland, the Netherlands, Poland, Portugal, the Slovak republic, Slovenia, Spain, Switzerland and Turkey. Some data concerning China has also been collected. The study mainly focuses on the triadic patent with priority date, which is the indicator for assessing technological strengths of nations. Triadic patents are those patents registered in the triad regions, i.e. in North America, Europe, and Asia with "priority date" where priority date means that when a first application is submitted in a country - the priority - is then extended to other offices.

The definition of the triadic patent family as per the OECD is "A patent family: the same invention in order to be protected is registered in various countries as a set of patents. Triadic patent families are a set of patents registered in the EPO, the JPO and the USPTO. Numbers and per million inhabitants express triadic patent families."

The authors have a panel data. This can also be called longitudinal data or cross sectional time series data. This is data where multiple cases (for example people, countries, etc.) can be observed in different time periods (two or more in number). The information contained in such kind of data is of two types. The differences between the subjects are shown in the cross-sectional information. The time series are shown in the changes that occur within subjects over a period of time. With the help of panel data regression techniques one can take advantage of these various forms of information.

In this paper, the variables the authors are interested in are: the number of patents for each country "oecd_pat" which represent the dependent variable in our final model; the population level "pop"; the education level mainly as tertiary education expressed in thousands "ed3_1000", and as per cent "ed3_pcent" as an indicator for education policy and highest level of education completed by each person; the expenditure for each country in R\&D (in thousands and per cent) as gross domestic expenditure on R\&D "rd_mpps", and as a percentage of GDP "rd_gdp"; and the expenditure for R\&D personnel total "rd_per_tot", and only personnel researchers "rd_per_re". 
The patent stock "stock_pat" is computed using 5 percent, 10 percent and 15 percent depreciation rate ("stock5_pat", "stock10_pat", "stock15_ pat") and not using 20 percent as suggested in the literature. The patent stock for subsequent years - after the initial patent stock - is calculated using the formula $P s_{t}=P_{t}+(1-\partial) P s_{t-1} P s_{t}=P_{t}+(1-\partial) P s_{t-1}$ from 1990 to 2015 (1990 is the initial year). Descriptive statistics are presented in Table 1.

Table 1: Descriptive statistics

\begin{tabular}{|c|c|c|c|c|c|c|c|c|c|c|c|c|}
\hline \multirow[t]{2}{*}{ Variables } & \multicolumn{4}{|c|}{ Estonia } & \multicolumn{4}{|c|}{ Germany } & \multicolumn{4}{|c|}{ OECD countries } \\
\hline & Mean & S.D. & Min & Max & Mean & S.D. & Min & Max & Mean & S.D. & Min & Max \\
\hline oecd_pat & 2.37 & 2.09 & 0 & 7.11 & 5536.72 & 1392.88 & 1912.93 & 7637.78 & 572.01 & 1195.42 & 0 & 7637.78 \\
\hline ed3_1000 & 253.68 & 16.16 & 227.4 & 273.4 & 11613.83 & 650.08 & 10761.1 & 12563.7 & 2797.23 & 3459.43 & 33.3 & 13716.40 \\
\hline Ed3_pcent & 29.93 & 2.40 & 26.4 & 33.3 & 22.5 & 1.80 & 20.1 & 25.2 & 23.83 & 7.22 & 8.4 & 39.60 \\
\hline rd_mpps & 219.68 & 124.61 & 69.40 & 457.43 & 53934.15 & 10037.73 & 41015.75 & 71842.57 & 9068.56 & 13733.64 & 56.45 & 71842.57 \\
\hline rd_gdp & 1.17 & 0.53 & 0.57 & 2.31 & 2.45 & 0.24 & 2.13 & 2.87 & 1.59 & 0.83 & 0.33 & 3.91 \\
\hline rd_per_tot & 8444.69 & 1490.08 & 6531 & 10284 & 755525.5 & 82501.59 & 664731 & 860842 & 114287.6 & 145783.1 & 2180 & 860842 \\
\hline Re_per_re & 6145.69 & 1242.58 & 4458 & 7646 & 46616.3 & 62659.83 & 397130 & 549283 & 73047.12 & 84862.04 & 1321 & 549283 \\
\hline Stock_pat & 20.57 & 18.24 & 0 & 54.46 & 65143.02 & 41412.44 & 4132.85 & 127344.6 & 6619.41 & 16455.15 & 0 & 127344.6 \\
\hline Stock5_pat & 15.32 & 13.32 & 0 & 38.92 & 36058.28 & 17189.79 & 3926.21 & 54096 & 4405.49 & 9250.50 & 0 & 54096 \\
\hline $\begin{array}{c}\begin{array}{c}\text { Stock10_ } \\
\text { pat }\end{array} \\
\end{array}$ & 12.30 & 10.11 & 0 & 29.68 & 35979.05 & 17244.98 & 3719.57 & 54070.88 & 3668.92 & 8435.31 & 0 & 54070.88 \\
\hline $\begin{array}{c}\text { Stock15 } \\
\text { pat }\end{array}$ & 10.15 & 7.99 & 0 & 23.60 & 28350.38 & 12167.23 & 3512.92 & 40944.64 & 2896.96 & 6504.78 & 0 & 40944.64 \\
\hline
\end{tabular}

\section{Research Design (or empirical analysis)}

The estimation of innovation has been carried out using a fixed-effects estimator. The fixed-effects (FE) regression analysis accounts for country fixed effects. It brings forth consistent estimators of the coefficients. It assumes that the intercepts change along with the countries. The model used is the following: 
( $\log \dot{P}_{i, t}=\beta_{0}+\alpha \ln H_{i, t}+\beta_{1} \ln R_{i, t}+\gamma \ln S P_{i, t}+\varepsilon_{i, t}$

Where $\log \dot{P} \log \dot{P}$ is the level of patents, $\log H \log H$ is the level of tertiary education, $\log R \log R$ represents the R\&D and $\ln S P \ln S P$ is the stock of patents. The subscripts $i, t$ refer to country and time level.

The authors pooled the above data to estimate the fixed effect model. In addition, the authors present results using the linear regression model and random effect model (RE). The authors test their models by the Hausman test and the significance of the $p$-value shows them that the model they should prefer is the FE model. Results of the authors' estimations are presented in Table 2. The authors also proceeded to estimate the level for the variables that are described in columns 1-3, while the relative values for the variables are presented in column 4 and column 5.

\section{Results}

In this section the authors present their results for the panel regression of 26 countries that are members of the OECD, for the years $1990-2015$. The authors estimate the linear regression model, FE and RE models, using for the "variables in level" and "relative variables". The main variables the authors are interested in are the level of tertiary education, the R\&D and stock of patents and how they affect our dependent variable "oecd_ pat". The education level is strongly significant but with a negative effect on the number of patents.

The covariate related to R\&D shows a positive coefficient that is what the authors expect from their study: they interpret this result as the more R\&D and innovation there is in a country, the more patents the country has. The level of stock patents shows a negative coefficient and are also not statistically significant. The goodness-of-fit is expressed by R-squared for the overall model, within and between countries, and tell the authors how the model is good to explain their prediction. 
From the authors' study, the R-squared is quite low and this means that the model is poor at explaining the number of patents. However, the overall R-squared and between R-squared are quite high (0.47 and 0.59). The authors interpret these results as the most obvious explanation: bigger countries invest more and then they have more patents.

The authors can also add that the education level, mainly tertiary education level, has a negative impact on the number of patents as they can see from the negative value of their estimations, while R\&D shows a positive coefficient. The authors' conclusion about those values can be related to the increase of the number of students in universities during the last decades.

The authors proceeded to test their FE and RE models by the Hausman test and as they already mentioned, $\mathrm{p}$-value is significant so they reject the null hypothesis that it is related to using the random effect model (Prob $>$ chi2 $=0.0000$ ).

Table 2: Estimations for level and relative variables

\begin{tabular}{|c|c|c|c|c|c|}
\hline Variables & OLS (1) & FE (2) & RE (3) & FE (4) & RE (5) \\
\hline \multirow{2}{*}{ Education level } & $-0.605^{* * *}$ & $-1.585^{* * *}$ & $-0.566^{* *}$ & $-1.477^{* *}$ & $-0.347^{* *}$ \\
& $(0.087)$ & $(0.359)$ & $(0.200)$ & $(0.521)$ & $(0.139)$ \\
\hline R\&D & $1.667^{* * *}$ & $0.727^{* *}$ & $1.417^{* * *}$ & $0.730^{*}$ & -0.000 \\
& $(0.084)$ & $(0.240)$ & $(0.180)$ & $(0.380)$ & $(1.124)$ \\
\hline $\begin{array}{c}\text { Stock patent } \\
\text { depreciated 5\% }\end{array}$ & $0.000^{* *}$ & $-0.000^{* *}$ & 0.000 & -0.280 & $0.911^{* * *}$ \\
\hline Constant & $-4.761^{* * *}$ & $10.551^{* * *}$ & $-3.018^{* *}$ & $-9.923^{*}$ & $-2.124^{* *}$ \\
\hline R2 (overall) & $(0.374)$ & $(2.016)$ & $(0.921)$ & $(4.760)$ & $(0.704)$ \\
\hline R2 within & ---88 & 0.46 & 0.88 & 0.47 & 0.90 \\
\hline R2 between & --- & 0.17 & 0.00 & 0.10 & 0.03 \\
\hline N. obs & 215 & 0.50 & 0.93 & 0.59 & 0.99 \\
\hline
\end{tabular}

Notes: $* 10 \%, * * 5 \%, * * * 1 \%$ level. Level variables are in columns (1)-(3) while relative variables are in columns (4)-(5)

The paper shows graphically the number of patents for all countries (Fig. 1) and for each country (Fig. 2). The highest number of patents belong to Germany, France, United Kingdom and Sweden. 
For the purpose of the authors' study which focuses on small member states such as Estonia, it is visible how the number of patents is quite low, but Estonia is on the bottom of the graph with other European countries such as Finland, Italy, or Luxembourg for example.

\section{Analysis}

Education is strongly significant but negative. R\&D and the stock of patents are both significant and positive as expected. Overall r-squared is very high. Between is also incredibly high (maybe because countries are just too different). R-squared within is incredibly low (when making countries comparable, the model is poor at explaining the number of patents). This suggests that the model is good at explaining the obvious: bigger countries invest more, and then have more patents.

Prior belief with the pooled model: more education leads to more patents. More R\&D leads to more patents. But data analysis shows that more education leads to less patents (educ coef is -2.42392, 0.002 in table is significant). One possible explanation is that there has been an expansion in the number of students in universities, and more are studying soft sciences. 50 years ago access to universities was restricted. Now everyone can access higher education. Therefore there is need to improve the quality of science taught in universities.

To have more patents (especially for high quality inventions) small member states such as Estonia need a university education system which leads to inventions which lead to patents. Quality of education matters. Patent acquisition assistance and guidance is needed - especially from a comparative perspective, in which the Baltic States and further East face an urgent need from various perspectives, as outlined by Hoffmann (2014). The data analysis shows that in the Baltics plus Finland, the bigger share of spending on R\&D is good for patents. Of course, already having a stock of patents makes it easier to get more patents. 
As has been stated by some scholars, a higher level of education can theoretically mean that more productive researchers are created. That same study also indicates that assessment of relative innovation performances of countries can be better assumed when one takes into account international patent filings. Another key feature is to focus on issues related to technological specialisation, since the propensity to patent varies on the type of industry. There is no denying that education policies contribute towards generating high quality researchers and equally high quality productivity. This is a result of the positive impact of the human capital index (Gaetan de Rassenfosse and Bruno Potterie 2009).

When one looks at the dismal situation in Estonia with regard to triadic patenting activities, it is apparent that international patenting activities need a push to prevent R\&D and the economy from languishing/ stagnation. The ranking system developed by the authors shows that Estonia is at the bottom as far as triadic patents are concerned. To corroborate the findings in the authors' present study, one can look at the recently published Industry Level Analysis Report, dated October 2016, compiled by the EPO and EUIPO. Chapter 7.4 reveals Member State by Member State analysis. Table 37 reveals that Estonia is ranked 22nd out of 28 countries when it comes to patent filings. This is marginally better than what the present study shows about Estonian triadic patent filings. There are no surprises that Germany occupies the first place for patents, trade marks and designs, followed by France, the Netherlands, the UK, etc. As the Report acknowledges that large countries tend to have more IPR filings, the table also shows IPR filings per 1000 employees. Estonia fares at 0.06 patents per 1000 employees in contrast with Germany which has 0.68 patents per 1000 employees.

This raises the question as to what exactly is going on within Estonia. On the one hand, it is easy to discredit the present research by stating that Estonia is a small country and more reliance should be placed upon per capita numbers. However, the triadic research data indicates that bigger (and richer) countries such as Denmark, Finland, Norway, Luxembourg, Belgium, etc. are similarly ranked as Estonia in this regard. So perhaps it is not a question of size or wealth, but rather some other characteristics. 
This has been the question of several researche projects conducted locally within Estonia, who seem to indicate the following:

a. Some Estonian researchers blame this sorry state of affairs regarding patenting activities in general in Estonia upon the legacy of the occupation by the Soviet Union. Since Independence Estonia has adopted a liberal stance but is saddled by a poor economy which cannot afford to support startups (especially technology based startups) as vigorously as neighbouring Western countries. Furthermore, in small countries like Estonia, IPR is perceived as a barrier to internationalisation or as a blocker for constraining competitors while its role as a supporter towards the market and knowledge leverage is grudgingly acknowledged. The use of clever business models (as adopted by Skype, etc.) and a happy combination based very often on luck is seen as the path forward (Mets and others 2010: 387, 388 and 393).

b. Interesting research based on case studies further revealed that while a few Estonian startups do make heavy use of IPR protection, this is rare and is affected by local attitudes within businesses towards a lack of flexible IPR reward regimes, being based more on rigid imperative legal norms instead of contractual arrangements with the employed scientists and engineers (Mets and Kelli 2013: 101-103).

c. Other researchers have shown Estonian statistical data points towards the fact that Estonian entrepreneurs, as a rule, tend to be SMEs in low-tech sectors. This is also a key reason why the level of patenting by Estonian entrepreneurs is generally low and the focus tends to be more towards protecting proprietary knowledge by using inefficient trade secrets. This approach, in turn, is harmed by the trade secrecy protection strategies adopted by Estonian businesses (Kelli and others 2010: 318, 322-324).

\section{Conclusion}

Countries like Estonia have very small economies and mostly trade in 
goods. In 2016, Statistics Estonia states that Estonian exports were mainly of electrical equipment, wood, agricultural and food products. Small EU member states such as Estonia and also medium EU member states, need to shift focus towards high technology services and new areas of Information and Communication Technology (ICT) and software applications. The policy implications that one can draw are similar to those stated by other researchers (de Rassenfosse and van Pottelsberghe de la Potterie 2009: 788), namely:

a. Small member states such as Estonia and also medium sized EU Member States should adopt a more coordinated approach when it comes to influencing researchers and their productivity vis-a-vis the propensity to patent, especially in high technology areas.

b. In view of the high costs incurred to acquire international patents (especially triadic patents), the governments of small and medium sized Member States should look towards ways to reduce the cost burden on their companies (especially start ups).

c. The triadic patent statistics provided by OECD are the least biased indicators of innovation performances and help in deducing international comparisons easily. Furthermore, the authors claim that small member states such as Estonia and also medium sized member states, should follow the example of countries such as Germany and adopt policies which focus more on increased public spending on R\&D and innovation in public universities of science and technology, and raise support for high tech startups. In this connection one could see details of Project Management Jülich which is one of the leading project management agencies in Germany, which integrates national and European funding measures with the aim of enhancing Germany's competitiveness as a prime location for research and innovation in the common European Research Area. It allocated $€ 1.41$ billion of funding during the 2015 financial year.

China is increasingly catching up with the West in regards to research, development and innovation, as well as international patenting. Chinese domestic laws are fully WTO compliant and are rapidly assuming a global influence (Hoffmann and Wang 2016). Furthermore, the trade deficit 
between China and the EU is growing rapidly in respect of goods, but not in respect of services according to Eurostat. If the markets of small and medium sized Member States fail to allocate sufficient resources towards generation of knowledge because their start-ups are financially unable to establish or defend/enforce their IPRs, then it becomes a classic case of the private rate of return to innovation becoming less than the the social return, which would then imply that the governments of such Member States must go further and subsidise R\&D, especially in public universities and university spin-offs (Pessoa 2005). This would be the only way for member states such as Estonia to become proficient in high technology applications and ICT services, thereby avoiding becoming economically irrelevant. This is especially important since they cannot possibly hope to compete economically against the flood of more competitively priced Chinese goods imported into the EU (which to a certain extent still depend upon cheap labour and are mass produced) thanks to, among others, the Chinese Belt and Road Initiative.

\section{ANNEXES:}

Figure 1: The number of triadic patents for all countries together. Note the colours in the graph:

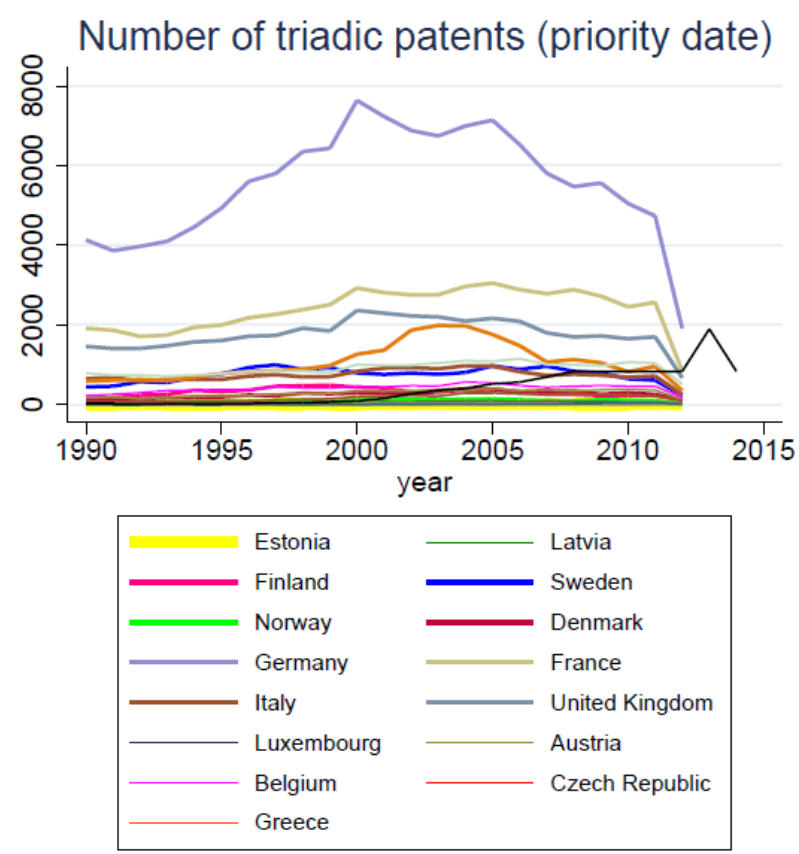


1. Estonia: Yellow

2. Latvia: Green

3. Finland: Pink

4. Sweden: Blue

5. Norway: Lime

6. Denmark: Cranberry

7. Germany: Lavender

8. France: Khaki

9. Italy: Sienna

10. United Kingdom: emidblue

11. Luxembourg: Navy8

12. Austria: Brown

13. Belgium: Magenta

14. Czech Republic: Red
15. Greece: Orange red

16. Hungary: Navy

17. Iceland: Sand

18. Ireland: Forest green

19. Netherlands: Dark orange

20. Poland: Teal

21. Portugal: Cranberry

22. Slovak Republic: Lavender (not visible because low part of the graph)

23. Slovenia: Khaki (idem as Slovak)

24. Spain: Sienna (same as 23 and 24)

25. Switzerland: Olive teal

26. Turkey: Emerald

27. China: Black

Figure 2: The number of triadic patents for all countries individually

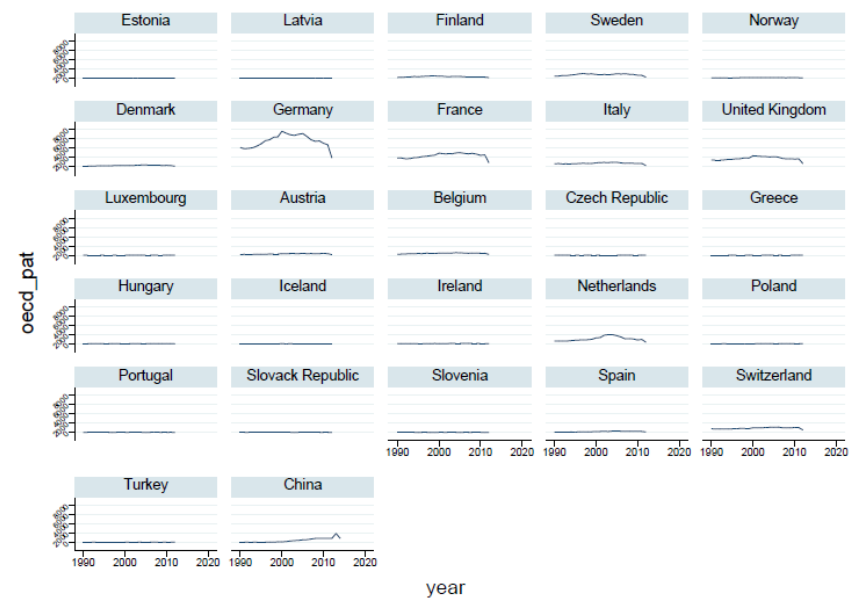




\section{$\Omega$ Bibliography}

Basberg, B., 1987. Patents and the measurement of technological change: a survey of the literature. Research Policy, 16(2-4): 131-141.

de Rassenfosse, G. and van Pottelsberghe de la Potterie, B., 2009. A policy insight into the R\&D - patent relationship. Research Policy, 38: 779792.

de Rassenfosse, G. and others, 2013. The worldwide count of priority patents: A new indicator of inventive activity. Research Policy, 42(3): 720-737.

Diamond v. Chakrabarty [1980] 447 U.S. 303.

Dobrin, S. and Chochia, A., 2016. The Concepts of Trademark Exhaustion and Parallel Imports: A Comparative Analysis between the EU and the USA. Baltic Journal of European Studies, 6(2): 28-57.

Dutt, P. and Kerikmäe, T., 2014. Concepts and Problems Associated with eDemocracy. In: Kerikmäe, T., ed. Regulating eTechnologies in the European Union: Normative Realities and Trends. Springer Verlag. pp. 285-323.

Estonian Patent Office, 2017. Tööstusomandi õiguskaitse ajaloost Eestis. [online]. Available at: http://www.epa.ee/et/ametist/ toostusomandi-oiguskaitse-ajaloost-eestis [Accessed 6 March 2017].

EUROPA, 2017. Estonia. [online]. Available at: http://europa.eu/ european-union/about-eu/countries/member-countries/estonia_ en [Accessed 6 March 2017].

European Patent Office and the European Union Intellectual Property Office, 2016. Intellectual property rights intensive industries and economic performance in the European Union. [pdf]. Available at: https://euipo.europa.eu/tunnel-web/secure/webdav/guest/ document_library/observatory/documents/IPContributionstudy/ performance_in_the_European_Union/performance_in_the_ European_Union_full.pdf [Accessed 6 March 2017]. 
Eurostat, 2017. National accounts and GDP. [online]. Available at: http:// ec.europa.eu/eurostat/statistics-explained/index.php/National_ accounts_and_GDP [Accessed 6 March 2017].

Geieger, G., European Parlimentary Research Service, 2016. One Belt, One Road (OBOR): China's regional integration initiative. [pdf]. Available at: http://www.europarl.europa.eu/RegData/etudes/ BRIE/2016/586608/EPRS_BRI(2016)586608_EN.pdf [accessed 6 March 2017].

Eurostat, 2017. Record EU deficit in trade in goods with China of $€ 180$ billion in 2015. [press release] 12 July 2016. Available at: http:// ec.europa.eu/eurostat/documents/2995521/7553974/6-12072016BP-EN.pdf/67bbb626-d55f-4032-8c24-48e4c9f78c3a [Accessed 6 March 2017].

Griliches, Z., 1958. Research costs and social returns: hybrid corn and related innovations. Journal of Political Economy, 66(5): 419-431.

Griliches, Z., 1964. Research expenditures, education and the aggregate agricultural production function. The American Economic Review, 54(6): 961-974.

Griliches, Z., 1979. Issues in assessing the contribution of research and development to productivity growth. The Bell Journal of Economics, 10(1): 92-116.

Griliches, Z., 1998. Patent Statistics as Economic Indicators: A Survey. In: Griliches, Z., ed. R\&D and Productivity: The Econometric Evidence. University of Chicago Press. pp. 287 - 343.

Hoffmann, T. and others, 2012. Abstraktsioonipõhimõte Eesti ja Saksa intellektuaalse omandi õiguses. Juridica, 7: 535-542.

Hoffmann, T., 2014. Reflections on Opportunities for Comparative Private Law in Academia: Central and Eastern Europe. Review of Central and East European Law, 39(2): 191-209.

Hoffmann, T. and others, 2015. How to keep open-source based innovation approaches sustainable: a view from the intellectual property perspective. Entrepreneurship and sustainability issues, 2(3): 133141. 
Hoffmann, T. and others, 2016. Enforcing Chinese Antimonopoly Law in the Internet Industry: An Analysis with Special References to Baidu. com. China and WTO Review, 2(2): 223-256.

Index Mundi, 2017. European Union Economy Profile 2017. [online]. Available at: http://www.indexmundi.com/european_union/ economy_profile.html [Accessed 6 March 2017].

Kelli, A., 2010. Trade secrets in the intellectual property strategies of entrepreneurs: the Estonian experience. Review of Central and East European Law, 35: 315-339.

Kerikmäe, T. and Chochia, A., eds., 2016. Political and Legal Perspectives of the EU Eastern Partnership Policy. Springer International Publishing.

Kuttim, M., 2016. The role of spatial and non-spatial forms of proximity in knowledge transfer: A case of technical university. European Journal of Innovation Management, 19(4): 468-491.

Mets, T. and others, 2010. Intellectual property - lever or barrier for the globalisation of knowledge intensive SMEs of small country origin. Engineering Economics, 21 (4): 387-398.

Mets, T. and others, 2013. The impact of intellectual property reward regime on the competitiveness of innovative SMEs Economics and Business. Economics and Business, 24: 99-104.

Ministry of Foreign Affairs, Republic of Estonia, 2017. Estonian Economy Overview. [online]. Available at: www.vm.ee/en/estonianeconomy-overview [Accessed 6 March 2017].

Männasoo, K. and others, 2014. R\&D, Credit Constraints, and Demand Fluctuations: Comparative Micro Evidence from Ten New EU Members. Eastern European Economics, 52(2): 49-64.

Männasoo, K. and others, 2011. R\&D in Boom and Bust: Evidence from the World Bank Financial Crisis Survey. Tallinn: Eesti Pank.

Nyman-Metcalf, K., Dutt, P. K., Chochia, A., 2014. The Freedom to Conduct Business and the Right to Property: The EU Technology Transfer Block Exemption Regulation and the relationship between Intellectual Property and Competition Law. In: Kerikmäe, T., ed. Protection of Human Rights in the EU: Controversies and Challenges of the 
Charter of Fundamental Rights. Springer Verlag. pp. 37-70.

Pessoa, A., 2005. Ideas driven growth: the OECD evidence. Portuguese Economic Journal, 4(1): 46-67.

Pitta, L., 1992. Intellectual property laws in the former Soviet republics: a time of transition. Santa Clara High Technology Law Journal, 8(2): 499-505.

Prause, G., 2015. Sustainable business models and structures for industry 4.0. Journal of Security and Sustainability Issues, 5(2): 159-169.

Prause, G. and others, 2014. User Communities - Drivers for Open Innovation. FORESIGHT-RUSSIA, 8(1): 18-23.

Project Management Jülich, 2017. [online]. Available at: https://www.ptj. de/en/start [Accessed 6 March 2017].

Romer, P., 1990. Endogenous Technological Change. The Journal of Political Economy, 98(5): S71-S102.

Statistics Estonia, 2016. In October, export growth was supported by the exports of goods of Estonian origin. [press release] 9 December. Available at: http://www.stat.ee/news-release-2016-138 [Accessed 6 March 2017].

Zhang, X., 2011 . Patent development, R\&D intensity and human capital a study based on a panel data model. Bachelors thesis. Linnaeus University. Available at: https://www.diva-portal.org/smash/get/ diva2:421384/FULLTEXTO1.pdf [Accessed 6 March 2017].

Simona Ferraro (simona.ferraro@ttu.ee) is a University Lecturer, Teaching Assistant and doctoral candidate at the Department of Economics and Finance, School of Business and Governance, Tallinn University of Technology. She holds degrees from the University of Palermo, Italy (MSC Economics in 2005 and BSc International Cooperation and Development Economics in 2013). Her main research includes microeconomic theory and labour market, education of economics, social inequality. She has taught courses on 
Microeconomics for BA and MA courses and Development Economics for a MA course. Her research has been published in the Eesti Pank Working Paper and Journal of Policy Modeling. Currently, Simona Ferraro is team member for a Horizon 2020 project.

Pawan Kumar Dutt (pawan.dutt@ttu.ee) is a Lecturer at Tallinn Law School of Tallinn University of Technology. He teaches Intellectual Property Law. His educational background includes Bachelor's degrees in Chemistry and in Law (both from the University of Mumbai, India) and a Master of Arts in Law from Tallinn University of Technology. He is a doctoral student at the Estonian Business School. He is an advocate and solicitor and is a member of various law associations in India. He is registered as a Patent Attorney in the Indian Patent Office. He has practiced law since 1998. His areas of research are Intellectual Property Law and Competition Law and he has various publications related to these topics. He has been involved in several international projects concerning the study of this field and funded by USAID and the European Union, both within and outside Europe.

Tanel Kerikmäe (tanel.kerikmae@ttu.ee) is Professor in European Law and a Director of Tallinn Law School, Tallinn University of Technology. He is a board member of several high-ranked law journals and author of more than 150 articles and publications. Tanel has been active as an expert for public and private institutions, international organizations, being, for example, EU key expert in Central Asia. He has been teaching and supervising at several universities e.g. in United Kingdom, Vietnam, Switzerland, and is related to international research cooperation networks such as Folke Bernadotte Academy. Currently, prof. Kerikmäe is responsible for several projects such as Horizon 2020 and Development Aid projects to raise competitiveness in neighbourhood countries (Moldova, Georgia) in the light of EU best practices and visions. 